\title{
Occurrence and characteristic of methicillin-resistant Staphylococcus aureus on pig farms in the Czech Republic
}

\author{
Jan Bardoň ${ }^{1,2}$, Milan Kolář ${ }^{2}$, Renata Karpíšková3 ${ }^{3,4}$, Helena Žemličková3, \\ Marta Fridrichová ${ }^{3}$, Pavel Sauer², Zora Št’ástková ${ }^{4}$, Vojtěch Hanulík ${ }^{2}$ \\ ${ }^{1}$ State Veterinary Institute Olomouc, Czech Republic \\ ${ }^{2}$ Palacky University, Faculty of Medicine and Dentistry, Department of Microbiology, Olomouc, \\ Czech Republic \\ ${ }^{3}$ National Institute of Public Health, Prague, Czech Republic \\ ${ }^{4}$ University of Veterinary and Pharmaceutical Sciences Brno, Faculty of Veterinary Hygiene and Ecology, \\ Department of Milk Hygiene and Technology, \\ Brno, Czech Republic \\ Received December 22, 2010 \\ Accepted July 16, 2012
}

\begin{abstract}
In recent years, a negative trend of increasing prevalence of methicillin-resistant Staphylococcus aureus (MRSA) strains has been noted worldwide. In addition to their prevalence in humans, MRSA strains have also been detected in animals, both pets and food-producing animals, especially in pigs. At the same time, transmission of MRSA strains from animals to humans has been documented. This study brings results from the first nationwide survey on the prevalence of MRSA in herds of breeding pigs, carried out throughout the Czech Republic in accordance with the Commission Decision 2008/55/EC, including brief characteristics of isolates. In 2008, a total of 283 pooled samples (dust swabs from partitions between pens) from the holdings of breeding pigs were analyzed. In five cases, MRSA isolates were detected, with a prevalence of $1.8 \%$. All the isolated strains belonged to a single sequence type ST398. It may be said that at present, the prevalence of MRSA on pig farms does not pose a significant general epidemiological risk for the human population.
\end{abstract}

MRSA, bacterial zoonoses, sequence type, toxins, antibiotic resistance

Methicillin-resistant Staphylococcus aureus (MRSA) strains were first described in hospitalised patients in Great Britain (Jevons 1961). These strains rapidly spread worldwide, particularly in the 1980s and 1990s, and their epidemiological importance continues to grow. The important fact is an increasing amount of data on transmission of MRSA between animals and humans. Since 2005, MRSA has been reported in animals (Vos s et al. 2005). However, the first cases of detection had been described much earlier (Devriese et al. 1972). At present, these strains, livestock associated MRSA (LA-MRSA), are intensively monitored in veterinary medicine since colonized or infected animals may easily contribute to the spreading of MRSA strains not only to the staff but, in case of food animals, also to raw materials to be processed and consumed (Lee 2003). The LA-MRSA strains were reported in cattle, horses and poultry (Devriese and Hommez 1975; Seguin et al. 1999; Lee 2003) and especially in pigs (Vo s et al. 2005).

The first pan-European survey on the occurrence of MRSA in herds of breeding pigs was carried out in the EU member states in accordance with the Commission Decision 2008/55/ EC in 2008. Results of the survey in the Czech Republic, including characteristics of the isolates, are presented here.

\section{Materials and Methods}

Sample collection on pig farms

Samples of sterile swabs were collected in 2008 on 283 pig farms throughout all regions of the Czech Republic. Holding selection, sample collection and processing were carried out in accordance with methods published

Address for correspondence:

doc. MVDr. Jan Bardoň, Ph.D., MBA

State Veterinary Institute Olomouc

Jakoubka ze Stříbra 1, Olomouc, Czech Republic
Phone: +420585225641

Fax: + 420585222394

E-mail: jbardon@svuol.cz

http://actavet.vfu.cz/ 
in the Commission Decision 2008/55/EC. On each holding, 5 samples were collected to make a single pooled sample for laboratory analysis. The samples were collected from dust accumulated on metal partitions separating individual pens.

Sample analysis and methicillin-resistant Staphylococcus aureus culture

The method was in accordance with the Commission Decision 2008/55/EC protocol. In presumptive colonies grown on the chromogenic agar, colour and morphology of cultures in Gram-stained preparations were assessed. The colonies indicative of being MRSA were subcultured on blood agar (Oxoid). The MRSA strains were confirmed by a PBP2a latex agglutination test (MRSA-Screen test, Denka Seiken Co., Japan) with simultaneous identification of the mecA gene by PCR (Poulsen et al. 2003). The strains were stored in a kryobank (ITEST) at $-80{ }^{\circ} \mathrm{C}$ for later testing. One MRSA strain (labelled J3420) perished in the course of the study and was lost to further analyses.

Typing of methicillin-resistant Staphylococcus aureus

The PCR method was used to study the ability of MRSA strains to produce enterotoxins - detection of the sea, seb, sec, sed, see, seg, seh, sei and sej genes (Monday and Bohach 1999; Løvseth et al. 2004), exfoliatins ETA and ETB (Jackson and Iandolo 1986; Lee et al. 1987), PVL (Lina et al. 1999) and TSST-1 (Monday and Bohach 1999). Macrorestriction analysis using pulsed-field gel electrophoresis (PFGE) (Pantucek et al. 1996) was carried out using the SmaI restriction enzyme.

Additionally, staphylococcal chromosome cassette mec (SCCmec) types were studied in these strains (Milheirico et al. 2007), and spa typing (Harmsen et al. 2003) and multi locus sequence typing (MLST) (Enright et al. 2000) were performed.

Resistance to antimicrobial agents

The minimum inhibitory concentration (MIC) values for MRSA isolates to 15 antimicrobial agents were determined by the standard broth microdilution method (CLSI 2007) using a commercially available test (Trios) and by the Phoenix automated system (Becton Dickinson, USA). Isolates resistant to erythromycin and susceptible to clindamycin were examined using the disc diffusion test (D-zone test) with erythromycin ( $15 \mu \mathrm{g})$ and clindamycin $(2 \mu \mathrm{g})$ discs (Oxoid) according to the method of (Fiebelkorn et al. 2003) to detect inducible macrolide, lincosamide and streptogramin $\mathrm{B}\left(\mathrm{iMLS}_{\mathrm{B}}\right)$ resistance.

\section{Results}

Occurrence of methicillin-resistant Staphylococcus aureus on pig farms

Of the 283 studied samples, MRSA was detected in only five holdings. It means that the prevalence of MRSA in herds of breeding pigs in the Czech Republic was $1.8 \%$. All five isolates of $S$. aureus showed positive reaction to the presence of both the PBP2a protein and the mecA gene.

\section{Molecular typing}

None of the four MRSA strains available for further molecular characterization carried genes for the production of enterotoxins, exfoliatins, Panton-Valentine leukocidin and TSST-1. Using PFGE, all the isolates were classified as nontypeable (NT). Characteristics of the chromosome cassettes, spa and MLST are listed in Table 1.

All isolates showed ST398 and were closely related by spa typing. Two isolates shared spa type $\mathrm{t} 2346$, but they differed by SCCmec types.

\section{Resistance to antimicrobial agents}

Table 2 shows the minimum inhibitory concentration values for the studied antibiotics. With

Table 1. The molecular characteristics of methicillin-resistant Staphylococcus aureus from pig farms

\begin{tabular}{lccccccccccc}
\hline Isolate & SCCmec type & MLST type & \multicolumn{4}{c}{ Allelic profile } & \multicolumn{1}{c}{ spa type } & Tandem repeats \\
\hline J2692 & V & ST 398 & 3 & 35 & 19 & 2 & 20 & 26 & 39 & t034 & 08-16-02-25-02-25-34-24-----25 \\
J4160 & V & ST 398 & 3 & 35 & 19 & 2 & 20 & 26 & 39 & t2346 & 08-16-02-25-------- 34-24-24-25 \\
J4443 & V & ST 398 & 3 & 35 & 19 & 2 & 20 & 26 & 39 & t4659 & 08-16-02-25---------24-24-24-25 \\
J4491 & IV & ST 398 & 3 & 35 & 19 & 2 & 20 & 26 & 39 & t2346 & 08-16-02-25---------34-24-24-25 \\
\hline
\end{tabular}

SCCmec - staphylococcal chromosome cassette, MLST - multi locus sequence typing 
Table 2. Minimum inhibitory concentrations of the tested antibiotics

\begin{tabular}{lcccc}
\hline Antimicrobial & \multicolumn{4}{c}{ Strain no. / MIC (mg/l) } \\
\cline { 2 - 5 } agent & $\mathrm{J} 2692$ & $\mathrm{~J} 4160$ & $\mathrm{~J} 4443$ & $\mathrm{~J} 4491$ \\
\hline Chloramphenicol & 16 & 4 & 2 & 2 \\
Tetracycline & $>8$ & $>8$ & $>8$ & $>8$ \\
Erythromycin & $>4$ & $>4$ & $\leq 0.25$ & $>4$ \\
Clindamycin & $>4$ & $>8$ & $>4$ & iMLS $_{\mathrm{B}}^{*}$ \\
Ciprofloxacin & 4 & 0.5 & 0.5 & 0.5 \\
Gentamicin & 1 & $>8$ & 1 & $>8$ \\
Teicoplanin & $\leq 1$ & $\leq 1$ & $\leq 1$ & $\leq 1$ \\
Vancomycin & $\leq 1$ & $\leq 1$ & $\leq 1$ & $\leq 1$ \\
Tigecycline & $\leq 0.03$ & $\leq 0.03$ & $\leq 0.03$ & $\leq 0.06$ \\
Nitrofurantoin & 8 & 8 & 8 & 8 \\
Daptomycin & $\leq 1$ & $\leq 1$ & $\leq 1$ & $\leq 1$ \\
Co-trimoxazole & 1 & 1 & 16 & 1 \\
Fusidic acid & $\leq 2$ & $\leq 2$ & $\leq 2$ & $\leq 2$ \\
Linezolid & 1 & 1 & 1 & 1 \\
Rifampicin & $\leq 0.5$ & $\leq 0.5$ & $\leq 0.5$ & $\leq 0.5$ \\
\hline
\end{tabular}

*positive D test, MIC - minimum inhibitory concentration, $\mathrm{iMLS}_{\mathrm{B}}$ inducible macrolide, lincosamide and streptogramin $\mathrm{B}$ resistance the exception of the J4443 strain, the tested isolates were resistant to macrolides. In case of the J4491 strain, inducible clindamycin resistance was detected. Resistance to tetracycline was found in all isolates. All MRSA isolates were susceptible to vancomycin, teicoplanin, tigecycline, daptomycin, fusidic acid, nitrofurantoin, linezolid and rifampicin.

\section{Discussion}

LA-MRSA strains were found on pig farms in the Czech Republic. The results show that LA-MRSA has spread in herds of breeding pigs in the Czech Republic, similar to numerous other European countries. However, the prevalence detected in the Czech Republic is low (1.8\%) compared to that in other EU member countries participating in the study. For instance, MRSA prevalence rates in Italy, Belgium, Germany and Spain ranged from $35 \%$ to $50 \%$, depending on the farm types. On the other hand, the study found no LA-MRSA on pig farms in the United Kingdom (285 investigated farms), Sweden (202), Lithuania (82) and Ireland (189) (EFSA 2009). Methods described by the Commission Decision 2008/55/EC are concerned with analyzing environmental samples only. However, isolates obtained from dust may not objectively reflect the actual prevalence of MRSA in pigs or breeders and their family members.

The LA-MRSA strains were detected at five Czech farms located in 5 different districts. A close association with e.g. animal (staff) movement between these farms could not be reliably confirmed.

Molecular typing of the strains showed the presence of ST398 on Czech pig farms. Moreover, the spa types of Czech porcine MRSA strains are closely related to spa types t011 and t108, the most predominant ones among pig-related MRSA strains. Similar results were reported by most countries participating in the EU study (EFSA 2009). High clonality of MRSA strains from pigs was documented and porcine strains of ST398 were found in France, the Netherlands, Germany and Denmark (Armand-Lefevre et al. 2005; de Neeling et al. 2007; Guardabassi et al. 2007; Witte et al. 2007). Although the isolates of a clone represented by ST398 do not seem to be frequent in human MRSA isolates, several cases of colonization and infection in humans in contact with pigs were reported (Armand-Lefevre et al. 2005; Witte et al. 2007; EFSA 2009). MRSA ST398 can occasionally be introduced into hospitals as a result of community-acquired human infections (EFSA 2009). Isolation of methicillin-susceptible $S$. aureus (MSSA) isolates of ST398 belonging to the separate pig-related biotype from 3 bacteraemic cases suggests a high virulence potential of these strains and close surveillance of ST398 human infections is highly advocated (van Belkum et al. 2008). In the Czech Republic, a study of nasal carriage of MRSA strains among veterinarians carried out in 2008 did not show the presence of ST398 among the screened persons (Zemlickova et al. 2009).

The ST398 MRSA sequence type is characterized by the presence of SCCmec types IV 
and $\mathrm{V}$, absence of genes responsible for production of enterotoxins, exfoliatins A and B, Panton-Valentine leukocidin and TSST (van Duijkeren et al. 2008). The ST398 type strains are not cleaved by restriction endonuclease SmaI and according to that characteristic they are nontypeable using PFGE. The presented results confirmed that the tested MRSA isolates did not carry any of the studied genes for enterotoxins, exfoliatins, PVL and TSST-1 toxins.

The tested isolates were resistant to at least four types of antibiotics. In accordance with results of Dutch a (de Neeling et al. 2007) study, all isolates were also resistant to tetracycline. Since tetracycline accounts for more than a half of the total amount of antibiotics used in Czech veterinary medicine (personal communication, Alfred Hera), resistance to tetracycline in porcine MRSA may be assumed to be directly associated with its preferential use.

The study presented results of the first official monitoring of LA-MRSA in pig farming in the Czech Republic. Presently, the prevalence of MRSA on pig farms (1.8\%) was very low compared to other European countries. All isolated strains belonged to a single sequence type, ST398, and none of the MRSA isolates carried genes for tested toxins. Monitoring of the occurrence of LA-MRSA should be recommended in other commodities (in particular milk and dairy products) directly entering the human food chain, from which $S$. aureus strains are frequently isolated.

\section{Acknowledgements}

This study was supported by the European Commission, the Czech Ministry of Education, Youth and Sports project no. MSM 6198959205, State Veterinary Administration, and research grant from the Internal Grant Agency, Ministry of Health (CZ), IGA 9642-4.

\section{References}

Armand-Lefevre L, Ruimy R, Andremont A 2005: Clonal comparison of Staphylococcus aureus isolates from healthy pig farmers, human controls, and pigs. Emerg Infect Dis 11: 711-714

Clinical and Laboratory Standards Institute 2007: Performance standards for antimicrobial susceptibility testing; Seventeenth informational supplement. CLSI document M100-S17.

Clinical and Laboratory Standards Institute, 940 West Valley Road, Suite 1400, Wayne, Pennsylvania 190871898 USA.

Commission Decision of 20 December 2007 concerning a financial contribution from the Community towards a survey on the prevalence of Salmonella spp. and methicillin-resistant Staphylococcus aureus in herds of breeding pigs to be carried out in the Member States. Official Journal of the European Union (notified under document number C (2007) 6579). 2008/55/EC.

de Neeling AJ, van den Broek MJ, Spalburg EC, van Santen-Verheuvel MG, Dam-Deisz WD, Boshuizen HC, van de Giessen AW, van Duijkeren E, Huijsdens XW 2007: High prevalence of methicillin resistant Staphylococcus aureus in pigs. Vet Microbiol 122: 366-372

Devriese LA, Hommez J 1975: Epidemiology of methicillin-resistant Staphylococcus aureus in dairy herds. Res Vet Sci 19: 23-27

Devriese LA, Vandamme LR, Fameree L 1972: Methicillin (cloxacillin)-resistant Staphylococcus aureus strains isolated from bovine mastitis cases. Zbl Vet-Med B 19: 598-605

EFSA 2009: Analysis of the baseline survey on the prevalence of methicillin-resistant Staphylococcus aureus (MRSA) in holdings with breeding pigs, in the EU, 2008. EFSA Journal 2010; 8(6): 1597; doi: 10.2903/j. efsa.2010.1597. Available at www.efsa.europa.eu

Enright MC, Day NP, Davies CE, Peacock SJ, Spratt BG 2000: Multilocus sequence typing for characterization of methicillin-resistant and methicillin-susceptible clones of Staphylococcus aureus. J Clin Microbiol 38: $1008-1015$

Fiebelkorn KR, Crawford SA, McElmeel M, Jorgsen JH 2003: Practical disk diffusion method for detection of inducible clindamycin resistance in Staphylococcus aureus and coagulase-negative staphylococci. J Clin Microbiol 41: 4740-4744

Guardabassi L, Stegger M, Skov R 2007: Retrospective detection of methicillin resistant and susceptible Staphylococcus aureus ST398 in Danish slaughter pigs. Vet Microbiol 122: 384-386

Harmsen D, Claus H, Witte W, Rothgänger J, Claus H, Turnwald D, Vogel U 2003: Typing of methicillin-resistant Staphylococcus aureus in a university hospital setting by using novel software for spa repeat determination and database management. J Clin Microbiol 41: 5442-5448 
Jackson MP, Iandolo JJ 1986: Sequence of the exfoliative toxin B gene of Staphylococcus aureus. J Bacteriol 167: $726-728$

Jevons MP 1961: Celbenin-resistant Staphylococci. Br Med J 1: 124-125

Lee JH 2003: Methicillin (oxacillin)-resistant Staphylococcus aureus strains isolated from major food animals and their potential transmission to human. Appl Environ Microbiol 69: 6489-6494

Lee CY, Schmidt JJ, Johnson-Winegar AD, Spero L, Iandolo JJ 1987: Sequence determination and comparison of the exfoliative toxin A and B genes from Staphylococcus aureus. J Bacteriol 169: 3904-3909

Lina G, Piémont Y, Godail-Gamot F, Bes M, Peter MO, Gauduchon V, Vandenesch F, Etienne J 1999: Involvement of Panton-Valentine leukocidin-producing Staphylococcus aureus in primary skin infections and pneumonia. Clin Infect Dis 29: 1128-1132

Løvseth A, Loncarevic S, Berdal KG 2004: Modified multiplex PCR method for detection of pyrogenic exotoxin genes in staphylococcal isolates. J Clin Microbiol 42: 3869-3872

Milheirico C, Oliveira DC, de Lancastre H 2007: Update to the multiplex PCR strategy for assignment of mec element types in Staphylococcus aureus. Antimicrob Agents Chemother 51: 3374-3377

Monday SR, Bohach GA 1999: Use of multiplex PCR to detect classical and newly described pyrogenic toxin genes in staphylococcal isolates. J Clin Microbiol 37: 3411-3414

Pantucek R, Gotz F, Doskar J, Rosypal S 1996: Genomic variability of Staphylococcus aureus and the other coagulase-positive staphylococcus species estimated by macrorestriction analysis using pulsed-field gel electrophoresis. Int J Syst Bacteriol 46: 216-222

Poulsen AB, Skov R, Pallesen LV 2003: Detection of methicillin resistance in coagulase-negative staphylococci and in staphylococci directly from simulated blood cultures using the EVIGENE MRSA Detection Kit. J Antimicrob Chemother 51: 419-421

Seguin JC, Walker RD, Caron JP, Kloos WE, George CG, Hollis RJ, Jones RN, Pfaller MA 1999: Methicillinresistant Staphylococcus aureus outbreak in a veterinary teaching hospital: potential human-to-animal transmission. J Clin Microbiol 37: 1459-1463

van Belkum A, Mells DC, Peeters JK, van Leeuwen WB, van Duijkeren E, Huijsdens WW, Spalburg E, de Neeling AJ, Verbrugh HA, Dutch Working Party on Surveillance and Research of MRSA-SOM 2008: Methicillinresistant and -susceptible Staphylococcus aureus sequence type 398 in pigs and humans. Emerg Infect Dis 14: 479-483

van Duijkeren E, Ikawary R, Broekhuizen-Stins MJ, Jansen MD, Spalburg EC, de Neeling AJ, Allaart JG, van Nes A, Wagenaar JA, Fluit AC 2008: Transmission of methicillin-resistant Staphylococcus aureus strains between different kinds of pig farms. Vet Microbiol 126: 383-389

Voss A, Loeffen F, Bakker J, Klaassen C, Wulf M 2005: Methicillin-resistant Staphylococcus aureus in pig farming. Emerg Infect Dis 11: 1965-1966

Witte W, Strommenger B, Stanek C, Cuny C 2007: Methicillin-resistant Staphylococcus aureus ST398 in humans and animals, Central Europe. Emerg Infect Dis 13: 255-258

Zemlickova H, Fridrichova M, Tyllova K, Jakubu V, Machova I 2009: Carriage of methicillin-resistant Staphylococcus aureus in veterinary personnel. Epidemiol Infect 10: 1-4 